\title{
Article \\ Experimental Investigation of Hydrous Ethanol Gasoline on Engine Noise, Cyclic Variations and Combustion Characteristics
}

\author{
Zhenbin Chen *, Jiaojun Deng, Haisheng Zhen (D, Chenyu Wang and Li Wang
}

check for

updates

Citation: Chen, Z.; Deng, J.; Zhen, H.;

Wang, C.; Wang, L. Experimental

Investigation of Hydrous Ethanol

Gasoline on Engine Noise, Cyclic

Variations and Combustion

Characteristics. Energies 2022, 15,

1760. https://doi.org/10.3390/

en15051760

Academic Editors: Yuhan Huang and

Hwai Chyuan Ong

Received: 25 January 2022

Accepted: 22 February 2022

Published: 26 February 2022

Publisher's Note: MDPI stays neutral with regard to jurisdictional claims in published maps and institutional affiliations.

Copyright: (C) 2022 by the authors. Licensee MDPI, Basel, Switzerland. This article is an open access article distributed under the terms and conditions of the Creative Commons Attribution (CC BY) license (https:// creativecommons.org/licenses/by/ $4.0 /)$
Mechanical and Electrical Engineering College, Hainan University, Haikou 570228, China; djjxueshu@163.com (J.D.); ban18@126.com (H.Z.); wcyxueshu@163.com (C.W.); w119970321@163.com (L.W.)

* Correspondence: zhenbin1208@hainanu.edu.cn; Tel.: +86-898-6626-7922

\begin{abstract}
Nowadays, the noise pollution of internal combustion engines is a very important factor influencing human health and is the main noise source of urban environmental noise. Additionally, the main source of gasoline engine noise consists of combustion noise in the cylinder, where the combustion noise is influenced by the combustion processes within the combustion chamber, especially the cyclic variation in the engine combustion. Thus, the inter-relationship between engine noise, cyclic variation and combustion is of great interest to be explored. Moreover, despite the environmental advantages of clean energy, the impact of different fuels on the internal combustion engine's noise emissions cannot be ignored. As a result, in this work, three blends were prepared and used as test fuels, namely pure gasoline (E0), 10\% hydrous ethanol (E10W) and 20\% hydrous ethanol (E20W) by volume, accompanied by engine operating at a steady speed of $2000 \mathrm{r} / \mathrm{min}$ under various loads. The experimental results show that lower engine noise was observed for both E10W and E20W compared to E0. Upon the addition of hydrous ethanol, the peak in-cylinder pressure increased while the maximum pressure rise rate $\left((d p / d \varphi)_{\max }\right)$ decreased at the low and medium loads. Furthermore, the coefficients of variation in indicated mean effective pressure $\left(C O V_{\text {imep }}\right)$ and $C O V_{(d p / d \varphi) \text { max }}$ for the two blended fuels were higher than those for pure gasoline. Compared with those of E20W, E10W has lower $C O V_{\text {imep }}$ and $C O V_{(d p / d \varphi) \text { max }}$ at low and medium loads. The $(d p / d \varphi)_{\text {max }}$ and noise emission have a positive relation when the engine is fueled with the hydrous ethanol-gasoline blends, whereas the cyclic variation parameters vary in the opposite direction of the noise emission level for all the blend mixtures. Moreover, $(d p / d \varphi)_{\max }$ has an essential effect on the combustion noise from a gasoline engine.
\end{abstract}

Keywords: hydrous ethanol gasoline; noise emissions; cycle-by-cycle variations; combustion characteristics; spark ignition engine

\section{Introduction}

For decades, internal combustion engines (ICEs) have been, and still are, one of the main power sources [1,2]. According to survey results, many countries attach more and more importance to the development and utilization of renewable and clean energy. Therefore, it has become a research hotspot to use renewable and clean biofuels to partially or completely replace gasoline and diesel. Moreover, the substitute fuel for internal combustion engines has been extensively studied with the aim to explore possible applications of oxygenated biofuels in ICEs. Among the oxygenated biofuel additives for spark-ignition engines (SIEs), one promising additive is ethanol. In the past few decades, ethanol has been widely used in many countries, especially in Brazil; ethanol has been in active use for more than 30 years, and, currently, about $85 \%$ of the flexible fuel vehicles in Brazil are fueled with ethanol or ethanol/gasoline mixtures [3].

While ethanol gasoline is widely used, experimental studies have also continuously confirmed the potential of ethanol as a vehicle fuel. The popular use of ethanol can be due to its superior physical and chemical characteristics. First, a high octane number of 
ethanol allows a high compression ratio, thus conducing to improve the thermal efficiency of the engine [4]. Meanwhile, ethanol has a high molecular oxygen content, promoting the combustion velocity and in-cylinder peak heat release rate [5]. Actually, the high flame speed of ethanol itself enhances the combustion progress in the engine cylinder and reduces the cycle-by-cycle fluctuations of the engine [6]. Further, ethanol has a cooling effect due to its high latent heat of vaporization, leading to a lower flame temperature and a lower NOx emission level [7].

It is known that the utilization of anhydrous ethanol as vehicular fuels is expensive as anhydrous ethanol is generally made from corn. Specifically, the production of anhydrous ethanol includes five phases: corn production, mashing and cooking, net energy gain in ethanol, distillation and dehydration [8]. It is clear that all these processes consume energy. Among them, water removal (distillation and dehydration) will produce the highest energy consumption, accounting for nearly $37 \%$ of the total energy consumed for anhydrous ethanol preparation [8]. Meanwhile, the strong hydrophilicity of anhydrous ethanol also increases the costs of anhydrous ethanol storage and transportation [9]. Therefore, it is quite obvious that a direct replacement of anhydrous ethanol by hydrous ethanol as a gasoline additive can be more economical.

Recently, some experimental studies regarding gasoline mixing with hydrous ethanol burned in an SI engine have been conducted, aiming to understand the impacts of blending biofuels oil on engine performance. The engine fueled with hydrous ethanol-gasoline mixtures (with water content of $6.8 \%$ ) designated as E22, i.e., $78 \%$ gasoline and $22 \%$ hydrous ethanol, was studied at different engine speeds [10]. They found that both the torque and brake mean effective pressure of E22 are higher than hydrous ethanol at the engine speed from $1500 \mathrm{r} / \mathrm{min}$ to $3500 \mathrm{r} / \mathrm{min}$. Besides, E22 emits less $\mathrm{NOx}$ and $\mathrm{CO}_{2}$ than hydrous ethanol does at the tested operations. Similarly, Roso et al. [11] found that the peak heat release rate of hydrous alcohol with water content from $4.9 \%$ to $4 \%$ is about $8 \%$ (E96W) higher than that of E27 (73\% gasoline and 27\% anhydrous ethanol). E96W emits less NOx and HC but more $\mathrm{CO}$ and $\mathrm{CO}_{2}$ in the range of an air-fuel ratio from 1 to 1.4. Schifter et al. [12] considered midlevel hydrous ethanol-gasoline blends. They pointed out that hydrous ethanol-gasoline mixtures have higher peak in-cylinder temperatures but lower in-take air temperatures than anhydrous ethanol at given operational conditions. Furthermore, the NOx emission decreased with the water concentration in the mixtures increasing. Compared with pure gasoline, they found that the emissions of NOx and HC are lower at low loads. Moreover, the total particle mass (PM) and count median diameter of hydrous ethanol-gasoline blends are lower [13].

Noise pollution, water pollution, air pollution and light pollution are regarded as four major environmental problems in the world. As a 'pollutant', the noise emission of SIEs burning hydrous ethanol-gasoline blends, which is a very important factor influencing human health and is the main noise source of urban environmental noise, is scarcely considered in the literature. It is partially due to the great difficulty in relocating the engine and test rig in an anechoic room, which is full of sound-absorbing flammable materials. As is known, an exposure to a noise level over $80 \mathrm{~dB}$ is extremely harmful to the human sense of hearing [14]. Additionally, in our previous study [15], we explored the effects of E20W fuel on the exhaust noise. The results show that hydrous ethanol-gasoline mixtures can dramatically decrease the noise emission level at a low engine speed. Due to the scarce work existent in this aspect, it is promising to further study the influence of engine load and hydrous ethanol addition on exhaust noise emissions.

The cycle-by-cycle fluctuation of the engine performance plays an essential role regarding engine combustion and emission characteristics [16]. It means that, when the engine runs stably under a certain working condition, the combustion process of this cycle and the next cycle is constantly changing, which is manifested in the difference in the pressure curve, flame propagation and engine power output. In general, a higher cyclic variation is related to lower power output and lower efficiency. Costa et al. [17] explored the correlation between the $C O V_{\text {imep }}$ and excess air ratio of an SI engine. They concluded that, when the 
excess air ratio increases from 1 to 1.6, the average effective pressure of ethanol increases linearly. Venugopal et al. [18] compared the $C O V_{\text {imep }}$ of an engine fueled with E10W or E0. The results displayed that, when the throttle opening is $25 \%$, the cycle change of E10W is smaller than that of pure gasoline. Similarly, Wang et al. [19] explored the effects of HE20 ( $20 \%$ hydrous ethanol) on the cycle-to-cycle variation in an SI engine. They concluded that the cyclic variations in HE20 are higher than E20 for two engine speeds at $1200 \mathrm{r} / \mathrm{min}$ and $1600 \mathrm{r} / \mathrm{min}$. However, a lower COV imep is observed for HE20 at $2000 \mathrm{r} / \mathrm{min}$. Noise pollution is a threat that can easily be ignored. In fact, the impact of noise on the environment and human health is a subtle, long-term impact. Therefore, the more invisible the influence, the more attention should be paid.

Actually, there have also been applications of alcohol fuels in compression ignition (CI) engines for decades [20,21]. Sathaporn Chuepeng et al. [22] found that acetone-butanolethanol-diesel blended fuel presents a slightly lower thermal efficiency and a longer ignition delay in a stock single-cylinder diesel engine compared to diesel fuel. Moreover, they discovered that the engine's thermal efficiency decreased as the quantity of ethanol injected into the inlet increased, and ethanol-diesel dual fuel is advantageous in smoke opacity but leads to increased NOx emissions [23]. Asad et al. [24] studied the effect of ethanol in low temperature combustion (LTC) mode in a single-cylinder light-duty diesel engine and observed higher levels of $\mathrm{HC}$ and $\mathrm{CO}$ emissions at low loads and ultra-low NOx and soot with diesel-like thermal efficiency. Chetankumar Patel et al. [25] investigated the effects of a single cylinder engine burning biodiesels on combustion, noise and vibration characteristics. They concluded that, the higher the heat release rate (HRR), the higher the magnitudes of combustion noise and external noise. Similarly, Giaokoumis et al. [26] reported slightly higher noise with a 30\% biodiesel blend compared to pure diesel.

As the literature review shows, much attention has been paid to studying the influences of different hydrous ethanol content in gasoline upon engine combustion and emission performance. However, as an engine is an important power device of transportation, reducing combustion noise is also worthy of attention as the core problem of automobile development. Although many researchers have done a great deal of research on combustion noise and its influencing factors, their analysis applies to diesel engines with various fuel mixtures. Furthermore, there exists a significant vacuum for studies exploring the performance of gasoline engines fueled with ethanol-gasoline blends from a noise standpoint and its correlation with the combustion characteristics, primarily because the inter-relationship of combustion characteristics and engine noise remains poorly understood [27]. As a result, the authors seek to fill this important gap through the work presented in this paper. For achieving this goal, the influence of ethanol-gasoline mixtures on gasoline engine noise, cycle change and combustion characteristics was carried out, paying more attention to their inter-relationships.

\section{Materials and Methods}

\subsection{Tested Fuels}

In this study, three fuel blends of hydrous ethanol and gasoline were tested: E0 (gasoline, commercial grade), which is also the baseline fuel, E10W (10\% hydrous ethanol plus $90 \%$ gasoline, by volume) and E20W. Hydrous ethanol, which is used as additive, contains $95 \%$ anhydrous ethanol and 5\% water by volume. The main physicochemical properties of hydrous ethanol and gasoline are illustrated in Table 1. As in our previous study [28], in order to have stable hydrous ethanol-gasoline blends, compound surfactants consisting of Span 80 and Tween 40 were selected, and castor oil was used as the solvent. The volume fractions of Span 80, Tween 40 and castor oil were $0.636 \%, 0.104 \%$ and $0.21 \%$, respectively. After the fuel preparation, both blended fuels were placed in a constant temperature and humidity chamber (QTH-2P-B) to test the fuel stability. Testing results showed that both blended fuels are stable for one month at ambient temperature. 
Table 1. Physical and chemical properties of test fuels.

\begin{tabular}{ccc}
\hline Fuel Properties & Gasoline [3,29] & Hydrous Ethanol [30,31] \\
\hline Density $\left(\mathrm{kg} / \mathrm{m}^{3}\right)$ & 748 & 809 \\
Oxygen content $(\% \mathrm{wt})$. & 0 & 36.8 \\
Viscosity $\left(\mathrm{mm}^{2} / \mathrm{s}\right)$ & 0.48 & 1.45 \\
Lower heating value $(\mathrm{MJ} / \mathrm{kg})$ & 44.11 & 25.23 \\
Latent heat of evaporation $(\mathrm{kJ} / \mathrm{kg})$ & 349 & 948 \\
Boiling point $\left({ }^{\circ} \mathrm{C}\right)$ & $25-230$ & 77 \\
Laminar flame velocity $(\mathrm{cm} / \mathrm{s})$ & 38 & 56 \\
\hline
\end{tabular}

\subsection{Experimental Conditions and Setup}

In this study, all the tests were constructed in the Automotive Power Laboratory of Tongji University. The test bench was equipped with an eddy current dynamometer (GW160), which was controlled by a DyneSystems DYN-LOC IV controller. The crank angle was recorded by a crankshaft signal sensor Kistler-2613B. A charge amplifier (Kistler-5015, Kistler, Winterthur, Switzerland) was employed to amplify the signals from the pressure transducer. The pressure data were recorded by a combustion analyzer (DEWE-5000, DEWETRON, Grambach, Austria) with the resolution of $0.5^{\circ} \mathrm{CA}$. Throttle position was controlled by a digital throttle controller (Dyne Systems DTC-1), and the main engine parameters are shown in Table 2.

Table 2. Main parameters of the test engine.

\begin{tabular}{cc}
\hline Type & Port Injection, Naturally Inspired \\
\hline Number of Cylinders & 4 \\
Bore $\times$ Stroke & $75.0 \mathrm{~mm} \times 84.8 \mathrm{~mm}$ \\
Compression ratio & 10.5 \\
Displacement Volume & $1.5 \mathrm{~L}$ \\
Maximum Power & $80 \mathrm{~kW}$ at $6000 \mathrm{r} / \mathrm{min}$ \\
Maximum Torque & $135 \mathrm{~N} \cdot \mathrm{m}$ at $4500 \mathrm{r} / \mathrm{min}$ \\
\hline
\end{tabular}

To measure the noise emitted in the gasoline engine exhaust gas, a noise acquisition system with a $\pm 0.01 \mathrm{~dB}$ accuracy was adopted. This system, the engine and its test rig were also located in a perfect anechoic room with a cut-off frequency of $80 \mathrm{~Hz}$. To simulate the situation of a nearby person, a microphone (B\&K; 4192, span from 20.7 161 dB) was placed $0.5 \mathrm{~m}$ away from the exhaust port with a vertical angle of $45^{\circ} \mathrm{CA}$. Then, the noise data were processed by fast Fourier transform (FFT) and A-weighting filter. The schematic experimental setup is depicted in Figure 1.

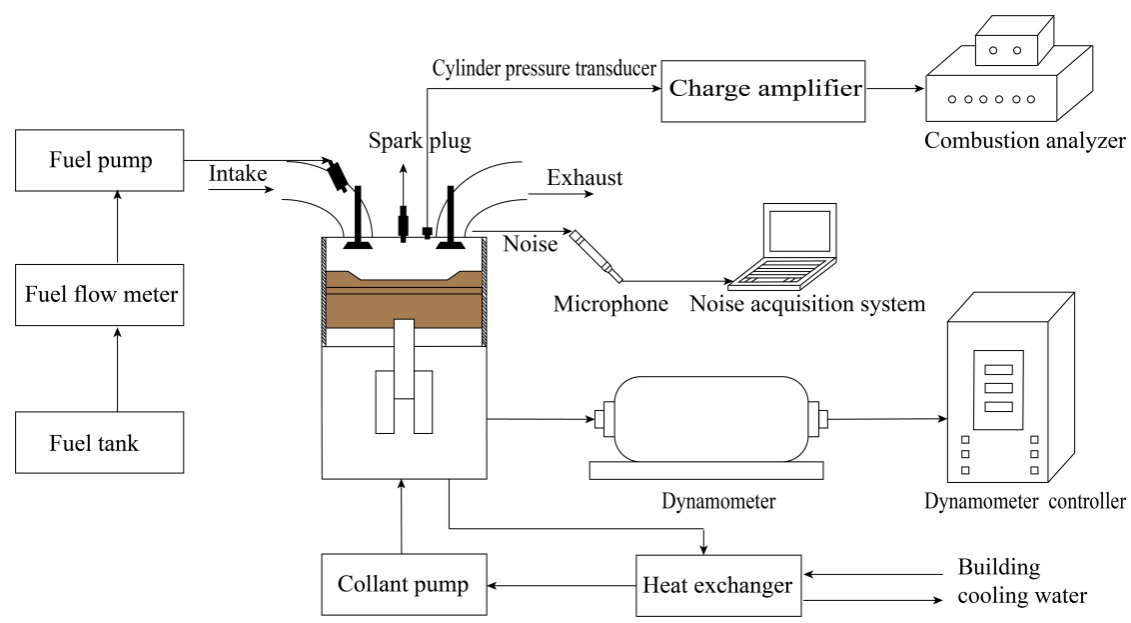

Figure 1. The schematic diagram of the experimental bench. 
Before the measurements, the engine was warmed up until both lubricating oil temperature and coolant water temperature achieved steady states. Notably, in our previous study [15], a better engine performance was observed at $2000 \mathrm{r} / \mathrm{min}$ engine speed condition. Thus, the engine speed was kept constant at $2000 \mathrm{r} / \mathrm{min}$ for all measurements to study the relationship between engine load and noise. For engine noise measurement, a wide engine load ranging from 0.04 to $0.84 \mathrm{Mpa}$ brake means effective pressure (BMEP) was tested. With regard to cyclic variations and engine performance, $0.17,0.42$ and $0.59 \mathrm{Mpa}$ BMEP are performed to represent the low, medium and high loads of the engine. For all measurements, the accuracy and uncertainty of the data are listed in Table 3.

Table 3. Accuracy and uncertainty of the measured data.

\begin{tabular}{cccc}
\hline Instrument & Parameters & Accuracy & Uncertainty \\
\hline \multirow{2}{*}{ Eddy current dynamometer } & Engine speed & $\pm 1 \mathrm{r} / \mathrm{min}$ & $\pm 0.5 \%$ \\
Piezoelectric pressure sensor & Engine torque & $\pm 0.2 \% \mathrm{~F} \cdot \mathrm{S}$ & $\pm 0.5 \%$ \\
Crankshaft signal sensor & Pressure & $\pm 0.01 \mathrm{MPa}$ & $\pm 0.2 \%$ \\
Microphone & Crank angle & $\pm 0.5^{\circ} \mathrm{CA}$ & - \\
Noise acquisition system & Engine noise & $\pm 2 \mathrm{~dB}(\mathrm{~A})$ & - \\
\hline
\end{tabular}

The overall uncertainty of the data reported in this study was calculated by the following equation [32].

$$
\text { overall experimental uncertainty }=\sqrt{\sum{\text { (Uncertainty of each parameters })^{2}}^{2}}
$$

Overall experimental uncertainty

$$
\begin{aligned}
& =\text { Square root of }\left[(\text { uncertainty of speed })^{2}\right. \\
& +(\text { uncertainty of torque })^{2}+(\text { uncertainty of pressure })^{2} \\
& \left.+(\text { uncertainty of noise })^{2}\right] \\
& =\text { square root of }\left[0.5^{2}+0.5^{2}+0.2^{2}+1^{2}\right]=1.34 \%
\end{aligned}
$$

\section{Results and Discussion}

\subsection{Noise Emissions}

Figure 2 illustrates the variation in the sound pressure level against engine load for three fuels under the constant engine speed of $2000 \mathrm{r} / \mathrm{min}$. At a constant speed, more fresh mixture injects into the combustion chamber with rising throttle opening. The pressure in the cylinder increases rapidly, which leads to the increase in stress in the mechanical parts. Thus, the sound pressure level of exhausted noise has an increasing tendency due to the gradually increasing engine load [25]. It can be obviously observed that the noise emitted by hydrous ethanol gasoline mixtures is lower than E0 at all loads.

To better understand the relation between the noise, cyclic variation and combustion performances of the engine, the noise data are analyzed in terms of low, medium and high loads. It is not difficult to see from Figure 2 that, when the engine load exceeds $0.50 \mathrm{MPa}$ BMEP, the noise emissions of both fuels, E0 and E10W, exceed $70 \mathrm{~dB}$. When the load exceeds $0.67 \mathrm{MPa} B M E P$, almost all three fuels exceed $70 \mathrm{~dB}$, even if the $\mathrm{E} 0$ reaches more than $75 \mathrm{~dB}$. At the low load, the sound pressure level of the blends is lower than the E0. The main reason can be that the exhaust noise sound pressure level is dominated by gas flow noise, which is controlled by the peak pressure in the cylinder at a low load [33]. The high latent heat of vaporization of hydrous ethanol reduces the in-cylinder peak temperature and peak pressure in the cylinder, where the latter acts as an important function in noise emission from the engine [14]. The sound pressure level of E20W is found to be higher than E10W at the low load. The longer ignition delay resulted in the higher ratio of hydrous ethanol in the blend fuels, leading to a higher pressure in the chamber [34]; thus, the sound pressure level emitted by E20W is higher than E10W. 


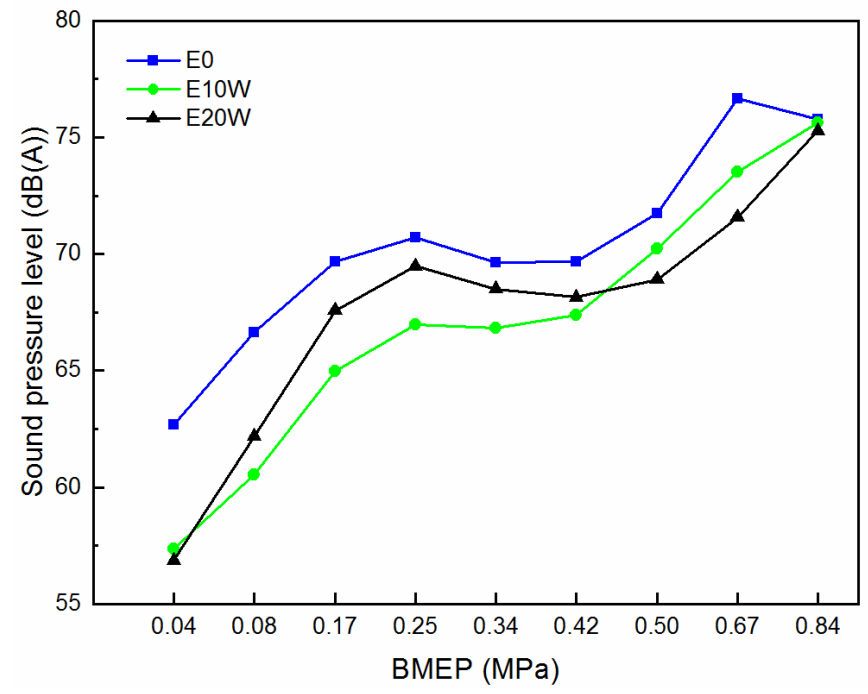

Figure 2. Noise emissions of three fuels at various loads.

At medium and high loads, the exhaust noise could be indicated by the exhaust back pressure, and a higher exhaust back pressure means that more potential energy could be converted into kinetic energy [15]. Figure 3 demonstrates the exhaust back pressures of the three tested fuels. As shown, the exhaust back pressure increases as the engine load increases. This is simply because, under higher engine loads, the gas motion in the chamber accelerates, leading to an increase in exhaust back pressure. At medium and high loads, stronger gas flow noise leads to heavier exhaust noise emission such that the exhaust back pressure becomes the most important factor influencing the exhausted noise due to the increased exhaust back pressure. As shown in Figure 3, E0 has the highest exhaust back pressure among the three fuels, followed by E10W and then E20W. It is clear that, at a high load, the variation trends in exhaust back pressure with engine load agree well with the variation in exhaust noise sound pressure level versus engine load. The lower exhaust back pressure of the hydrous ethanol-gasoline blends is mainly attributed to their oxygen content. Under identical experimental conditions, the higher oxygen content of the blend fuels results in a lower stoichiometric air-fuel ratio than the E0, and the actual air-fuel mixture burning hydrous ethanol-gasoline blends would be leaner than the case of the baseline fuel. Since the flammability velocity slows down as a consequence of leaner mixture in the cylinder [35], the exhaust back pressure decreases with decreasing pressure wave energy.

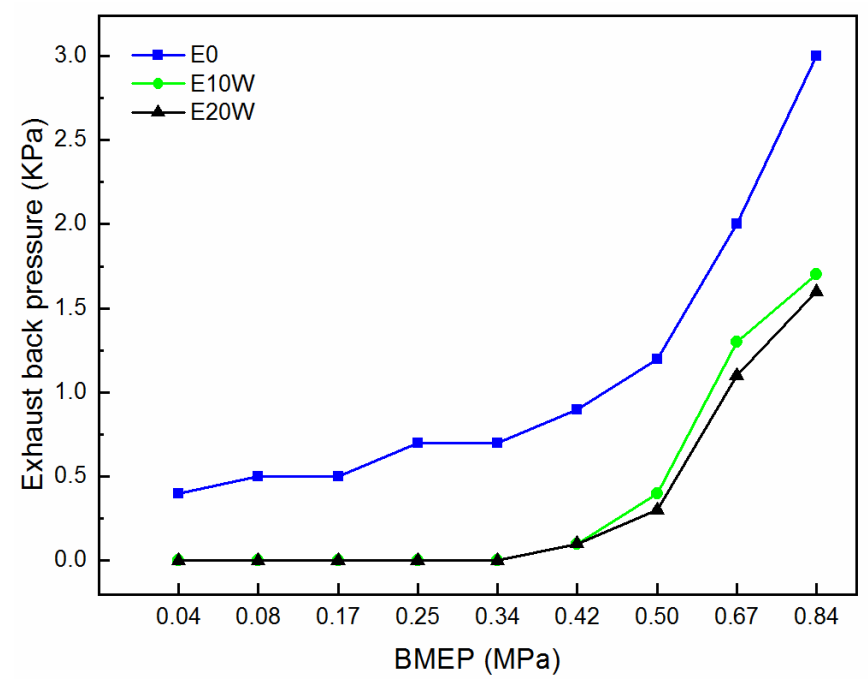

Figure 3. Exhaust back pressure of three fuels at various loads. 


\subsection{Combustion Characteristics}

\subsubsection{In-Cylinder Pressure}

As afore-mentioned, the noise emission is related to the peak in-cylinder pressure, and, thus, it is discussed in this section. Figure 4 presents the pressures of the in-cylinder for the three fuels under the different loads, and, as the load increases, the peak in-cylinder pressure (Pmax) rises for all fuels. When the engine load increases from 0.17 to $0.59 \mathrm{MPa}$ $\mathrm{BMEP}$, the peak pressures of E0, E10W and E20W increase by 1.21, 3.11 and $2.72 \mathrm{MPa}$, respectively. This is because more fresh charge enters the cylinder at higher engine loads, which promotes turbulence and increases in-cylinder pressure [36].

More importantly, Figure 4 indicates that, with the addition of hydrous ethanol under an identical engine load, at a low load, it is believed that the evaporation of hydrous ethanol absorbs heat from the cylinder, and, thus, the intake gas temperature is decreased, leading to the decrease in the Pmax for hydrous ethanol-gasoline blends. The high latent heat of vaporization of hydrous ethanol can decrease the gas temperature in the cylinder, which significantly changes the pressure fluctuation [9]. However, the in-cylinder temperature is increased to be much higher than the temperature at medium and high loads. Thus, the effect of high latent heat is fading away, and other factors, on account of the blends, contribute to higher peak in-cylinder pressure. These factors are discussed as follows. Firstly, due to the higher volatility and lower boiling point of ethanol, the droplet size of the blends decreases, which is beneficial for the combustion of the fuel-air mixtures in the chamber [37]. Secondly, the higher octane value of hydrous ethanol prolongs the ignition delay, leading to more mixtures in the combustion chamber. Thirdly, ethanol has a flame velocity 1.5 times higher than gasoline, which can accelerate the combustion processes in the cylinder. All these three factors can promote the combustion characteristics and thus result in a higher peak in-cylinder pressure. Figure 4 presents the Pmax of E10W, which is generally lower than that of E20W, consistent with the fact that E20W has a higher flammability velocity than E10W [38].

\subsubsection{Rate of Pressure Rise}

It is known that the pressure rise rate is also intimately related to the engine noise emission $[39,40]$. In order to explore the relation between engine noise and cycle-to-cycle variation, the engine's cyclic variation was designated by the rate of pressure rise discussed here. Figure 5 gives the pressure rise rates, $(d p / d \varphi)_{\max }$, for three various fuels under the different loads. As can be seen, the $(d p / d \varphi)_{\max }$ increases as the engine load increases. In such circumstances, the variation in $(d p / d \varphi)_{\max }$ is influenced by two factors, namely the heating value and latent heat of evaporation. Firstly, the lower heating value of hydrous ethanol contributes to a lower heat release rate. Therefore, the blend fuels have a lower pressure rise fluctuation according to the relation between the $(d p / d \varphi)_{\max }$ and maximum heat release rate $[36,41]$. This factor tends to play a dominant role for the value of $(d p / d \varphi)_{\max }$, which leads the $(d p / d \varphi)_{\max }$ for gasohol to be lower than that for gasoline. Secondly, the in-cylinder temperature is decreased due to the evaporation of hydrous ethanol [42], which is of minor significance. For example, the higher latent vaporization of E20W in comparison to E10W leads to a lower temperature. The sufficient low temperature will eventually increase the ignition delay. Accumulated air-fuel mixture due to delayed ignition will be ignited after the prolonged ignition delay; thus, the pressure rise rate is increased [14].

However, at a high load, an opposite trend is observed; i.e., the $(d p / d \varphi)_{\max }$ for gasohol is higher than that for gasoline. The reason may be the higher flammability velocity and more significant role of oxygen content in the fuels. At a high load, the decrease in incylinder pressure caused by the latent vaporization of the blend fuels is weakened. The higher molecular oxygen content promotes leaner and more complete combustion than the case of pure gasoline, which accelerates the combustion speed and enhances the rise in $(d p / d \varphi)_{\max }[5]$. Additionally, the combustion could be improved by the $\mathrm{O}, \mathrm{H}, \mathrm{OH}$ radicals dissociated from the rich hydrous ethanol-gasoline mixtures [13]. 

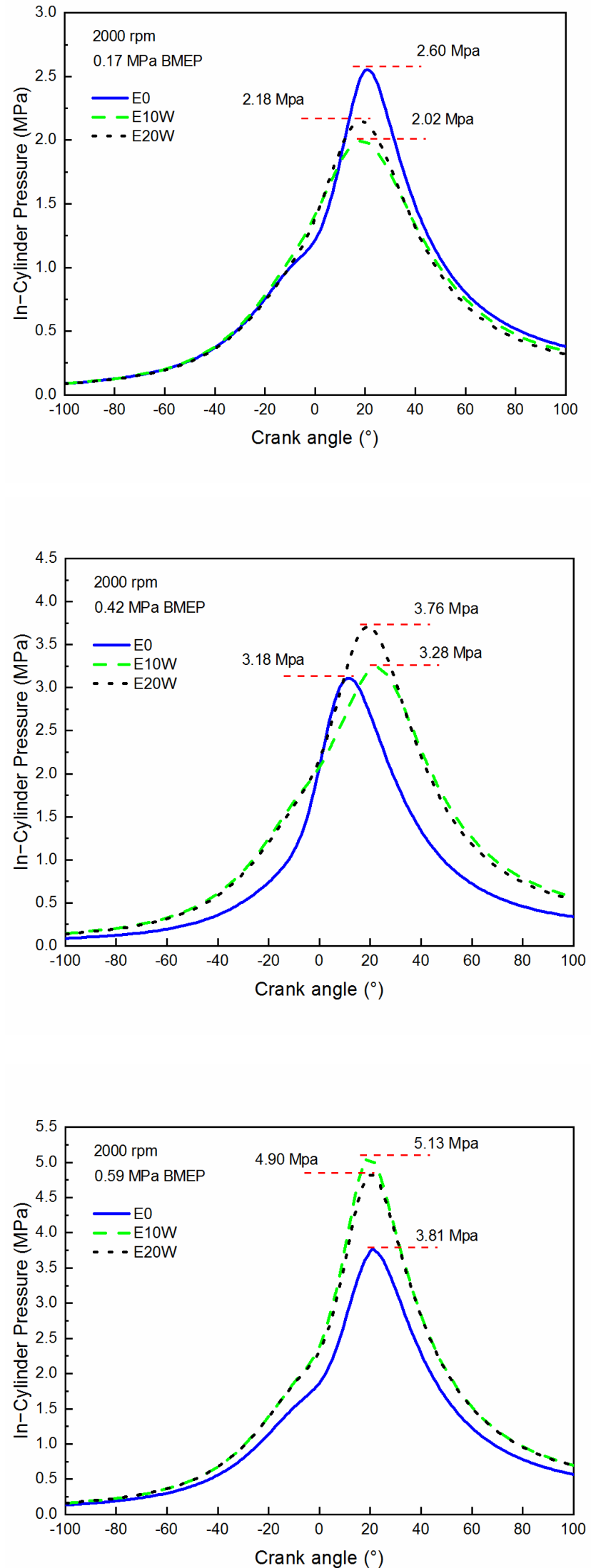

Figure 4. The average in-cylinder pressure of E0, E10W and E20W for three various loads. 

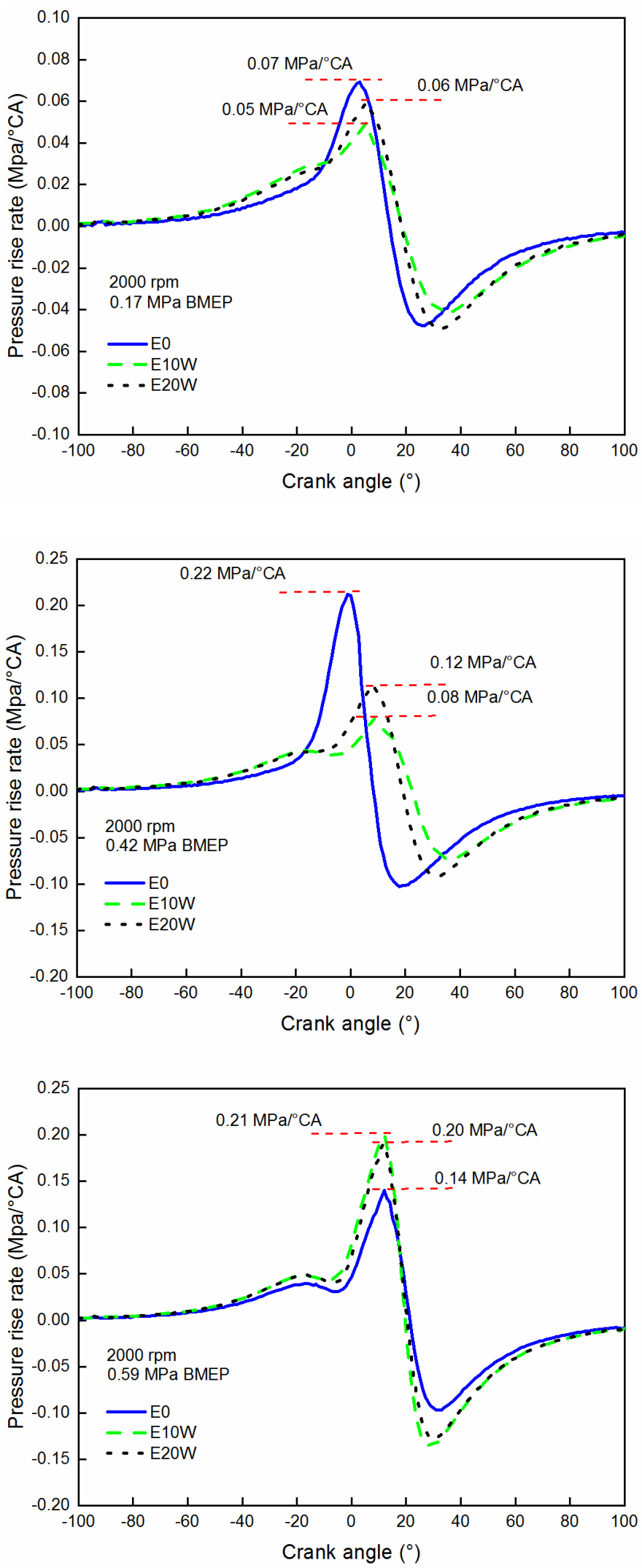

Figure 5. The average pressure rise rate of E0, E10W and E20W for three various loads.

\subsection{Cycle-by-Cycle Variations}

Combustion cycle variation is a major feature of the ignition engine combustion process, which is manifested in the pressure curve, flame propagation and engine power 
output, which are not the same. In this study, coefficient of variation $(C O V)$ was used as a typical indicator to evaluate the cycle change of SI engine. The COV of a parameter $(x)$ is calculated by the following formula:

$$
\begin{gathered}
\operatorname{COV}=\frac{\sigma}{\bar{x}} \times 100 \% \\
\sigma=\sqrt{\frac{\sum_{i=1}^{n}\left(x_{i}-\bar{x}\right)^{2}}{n-1}}
\end{gathered}
$$

where $\sigma$ is the sample standard deviation; $\bar{x}$ is the average value of $x$; $n$ is the number of different cycles.

\subsubsection{Cycle-by-Cycle Variations in IMEP}

Cycle-by-cycle variation in indicated mean effective pressure (IMEP) is an important parameter that characterizes the periodic variation in the vehicle. Additionally, when the $C O V_{\text {imep }}$ exceeds 10 percent, the drivability of the vehicle is found to be problematic [43]. Figure 6 displays the values of IMEP for three test fuels at $2000 \mathrm{r} / \mathrm{min}$ under three loads. As seen, the mean values of IMEP increase with the growth in engine load for the three fuels.

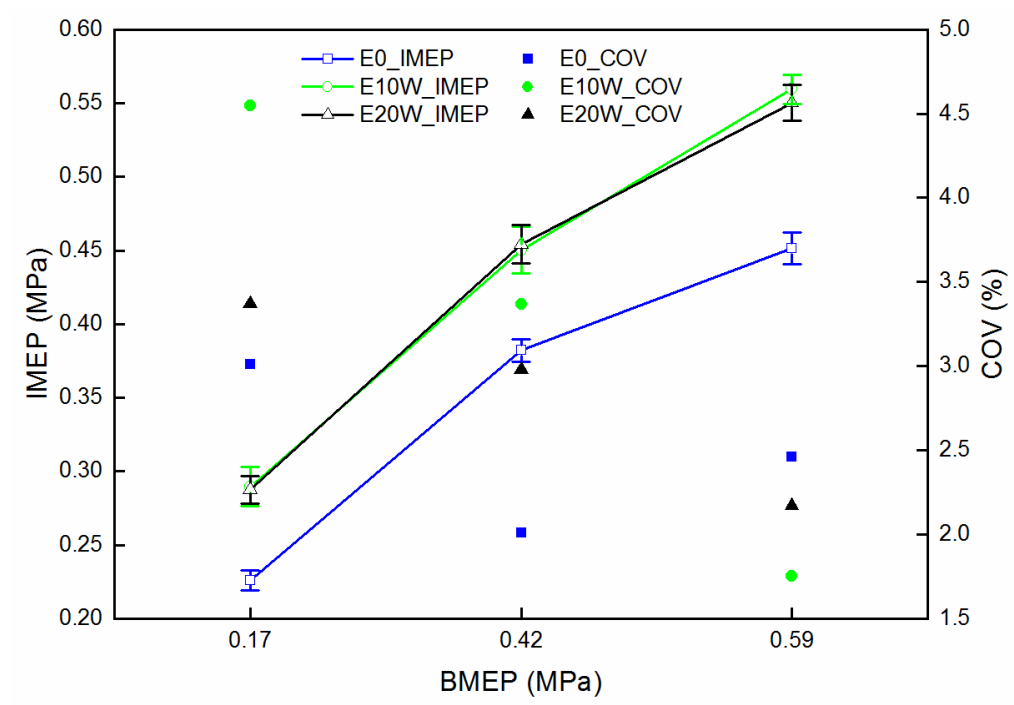

Figure 6. The cycle-by-cycle variations in IMEP for E0, E10W and E20W under three various loads.

Notably, E10W shows the highest $C O V_{\text {imep }}$ among the three fuels at low and medium loads. The higher latent heat of the blends is a major factor that influences the formation of fuel-air mixtures. This is due to the local cooling effects of the added hydrous ethanol, the vaporization rates of the blend fuels decrease at the end of compression stroke, incurring slower kernel growth and higher pressure fluctuation [44]. A second reason is that the addition of hydrous ethanol results in a longer ignition delay, which could accumulate more air-fuel mixture in the chamber. A delayed ignition leads to more violent pressure fluctuation; thus, the $C O V_{\text {imep }}$ becomes higher. Thirdly, the higher volatility of ethanol reduces the local equivalence ratio in the chamber, leading to the reduction in repeatable combustion cycles $[45,46]$ and, thus, an increase in the cycle-by-cycle variations. It is noticed that E20W gains a lower $C O V_{\text {imep }}$ than E10W at low and medium loads. This may be attributed to the much higher quantity of flammable radicals produced by the higher ratio of hydrous ethanol in the blended mixture; the burning velocity in the chamber is accelerated. According to the research of Sen A K [47], any factors that can increase burning velocity lead to the reduction in cyclic variations. Thereby, the $C O V_{\text {imep }}$ of E20W is lower than E10W. More details should be explored by other techniques, such as particle 
image velocimetry, schlieren and planar laser induced fluorescence and spark emission spectroscopy $[44,48]$.

In contrast, the two blended fuels of E10W and E20W show a lower $C O V_{\text {imep }}$ at a high load when compared to E0. At a high load, the effects of high latent heat of the blends become weaker due to the richer air-fuel mixture and higher in-cylinder temperature. Moreover, the higher laminar flame speed and the presence of oxygen in hydrous ethanol can improve the combustion, thus reducing the cyclic variation $[49,50]$. Further, the pressure fluctuation resulted by the ignition delay of hydrous ethanol is weaker than the pressure promotion caused by the larger throttle opening at a high load. As a consequence, the $C O V_{\text {imep }}$ decreased with the addition of hydrous ethanol under the high engine load condition. Especially, it is noticed that E20W attains a higher $C O V_{\text {imep }}$ than E10W at a high load. The main reason is that the higher ratio of hydrous ethanol in blend fuels is accomplished by a leaner air-fuel mixture; the change in IMEP is improved due to the increasing tendency of misfire. It should be mentioned that the distribution range becomes relatively wider with the addition of hydrous ethanol at a given load. Taking the load of $0.17 \mathrm{MPa}$ BMEP as an example, the concentrated values of IMEP for E0 range from 0.21 to $0.25 \mathrm{MPa}$, with $58.57 \%$ maximum repeatability of IMEP. Whereas, for E20W, the values of IMEP span from 0.26 to $0.32 \mathrm{MPa}$.

\subsubsection{Cycle-by-Cycle Variations in $(d p / d \varphi)_{\max }$}

The maximum pressure rise rate is not only used to investigate the knock tendency of SIEs but also to explore the maximum heat release rate in the cylinder and the heat transfer to the cylinder wall during the combustion progress [36]. A greater rate of pressure rise results in a larger tendency of the engine to knock. Therefore, it is reasonable to investigate how the cycle-by-cycle variations are influenced by the maximum pressure rise rate $\operatorname{COV} V_{(d p / d \varphi) \max }$. The effects of engine load and hydrous ethanol blending ratio on the $C O V$ of $(d p / d \varphi)_{\max }$ at $2000 \mathrm{r} / \mathrm{min}$ are studied. As reported in the literature, the cyclic variation decreases with increasing load. That is, higher cyclic variations are easier to be found at a low speed and low load conditions [6,49]. It is shown in Figure 7 that E10W has the highest cyclic variations in $(d p / d \varphi)_{\max }$ at low and medium loads, followed by E20W and E0. The COV (dp/d $)_{\text {max }}$ of E0 is lower than E10W and E20W by $16.85 \%$ and $8.66 \%$, respectively, at a low load. Meanwhile, the $C O V_{(d p / d \varphi) \max }$ of E0 is lower than E10W and E20W at a low and medium load. It should be noticed that the higher $C O V_{(d p / d \varphi) \max }$ of hydrous ethanol-gasoline blends can be induced by the following factors. Firstly, despite that higher latent heat for vaporization of ethanol can increase the volumetric efficiencies [51], the cyclic variations would be deteriorated by the negative effect of this property at low temperature conditions. The flammable radicals in the chamber are reduced by the lower intake temperature, leading to higher cyclic variation [36]. Secondly, a longer ignition delay caused by the addition of ethanol makes a contribution to more intensive pressure fluctuation. Thirdly, the high volatility of hydrous ethanol makes a contribution by lower cyclic variations. Note that the $C O V_{(d p / d \varphi) \max }$ of E10W is higher than that of E20W, which is due to the higher ratio of hydrous ethanol in E20W. The chain reaction is promoted by the more abundant $\mathrm{OH}$ radicals, which are formed in the development of dehydrogenation reaction of hydrous ethanol [52]. The flammability velocity of the fuels is accelerated, which decreases the $C O V_{(d p / d \varphi) \max }$ of E20W. Nevertheless, the $C O V_{(d p / d \varphi) \max }$ of hydrous ethanol is lower than E0 at a high load. This is due to the higher flammability, combustion rate and oxygen content of hydrous ethanol, as discussed above.

In order to have a deeper insight into the cyclic variation in the $(d p / d \varphi)_{\max }$, the distribution of peak pressure rise rates is examined in greater detail. At a given load, the difference between the blend fuels and gasoline is obvious, especially at high load. Citing E0 and E20W as an example, the $(d p / d \varphi)_{\max }$ of E0 at $0.59 \mathrm{MPa}$ BMEP remains from 0.04 to $0.24 \mathrm{MPa} /{ }^{\circ} \mathrm{CA}$. However, the values of E20W are widely distributed under the same load, and the maximum repeatability $(d p / d \varphi)_{\max }$ is about $7.14 \%$ in the range of $0.10 \sim 0.34 \mathrm{MPa} /{ }^{\circ} \mathrm{CA}$ at the same load. The more concentrated region of E0 is in agreement with the lower cyclic 
variation, as we discussed before. The higher latent heat of the vaporization of hydrous ethanol and lower heating value are detrimental for the growth of the initial kernel, thereby leading to a higher cyclic variation in $(d p / d \varphi)_{\max }$.

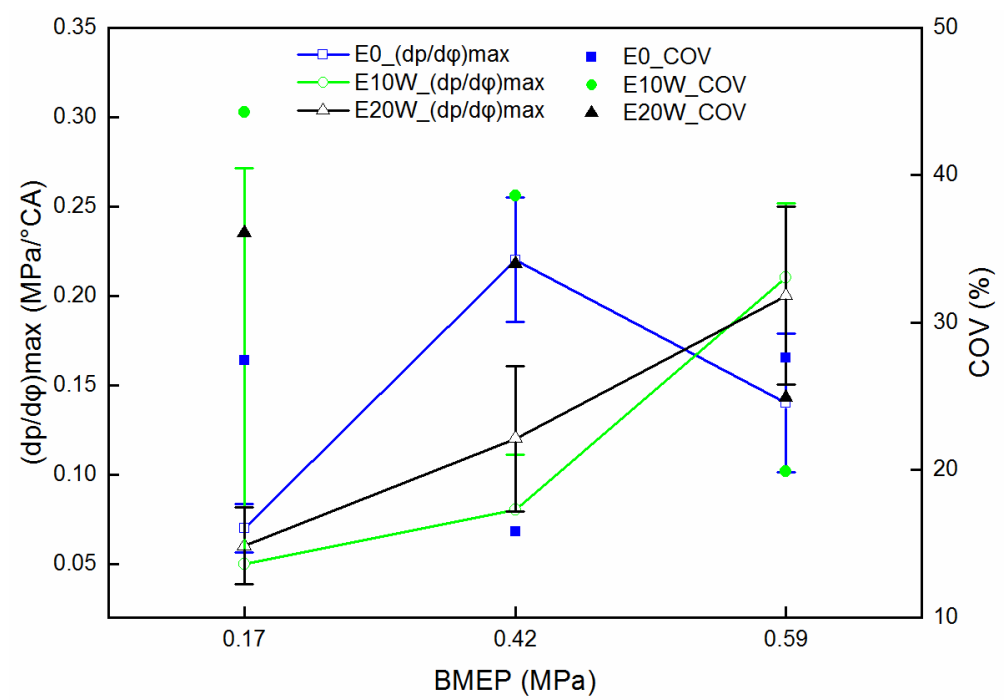

Figure 7. The cycle-by-cycle variations in $(d p / d \varphi)_{\max }$ for E0, E10W and E20W under three various loads.

\subsubsection{Cycle-by-Cycle Variations in Pmax}

According to previous studies that show that the combustion noise is produced during the rapid combustion period, the combustion chamber wall, piston, crankshaft and other related parts caused by cycle-by-cycle variations in pressure are subjected to strong dynamic loads [53]. Increasing the cylinder pressure of an internal combustion engine is helpful to improve the power of an internal combustion engine, increase the expansion output power and improve the energy conversion efficiency [54]. However, a larger in-cylinder pressure fluctuation brings considerable mechanical load, heat load and noise emission.

As shown in Figure 8, the effects of engine load and hydrous ethanol blending ratio on the $C O V_{P \max }$ at $2000 \mathrm{r} / \mathrm{min}$ are studied. Obviously, the COV Pmax of E10W and E20W describes a slight downward trend with an increase in load, and a little difference between the two test fuels is observed under all loads. This is because, with the increase in load, the increase in injection quantity promotes the combustion process in the cylinder, and the thermal expansion increases. However, it should be mentioned that the distribution range becomes relatively wider with the E0 at a given load. The $C O V_{P \max }$ of E0 shows a fluctuating result in terms of the trend of significantly increasing first and then remarkably decreasing, and the value of $C O V_{\text {Pmax }}$ up to $46 \%$ at $0.42 \mathrm{MPa} \mathrm{BMEP}$, about three times as high as E10W and E20W. Taking the load of $0.42 \mathrm{MPa} B M E P$ as an example, the concentrated values of Pmax for E0 range from 4.00 to $4.36 \mathrm{MPa}$, with $45.57 \%$ COV Pmax . Whereas, the $C O V_{\text {Pmax }}$ of E10W and E20W is $15.71 \%$ and $11.50 \%$. The main reason is that alcohol fuels generally have a high octane number, which can extend the ignition delay period. When the temperature and pressure in the cylinder are properly controlled, the combustion capacity can be improved. Secondly, due to the long ignition delay period and oxygen content in the molecule, stable combustion is further promoted. Finally, when the load is high, the water in the mixed fuel converts into steam at a high temperature, and the expansion work increases the cylinder explosion pressure, which improves the performance of the internal combustion engine [54]. 


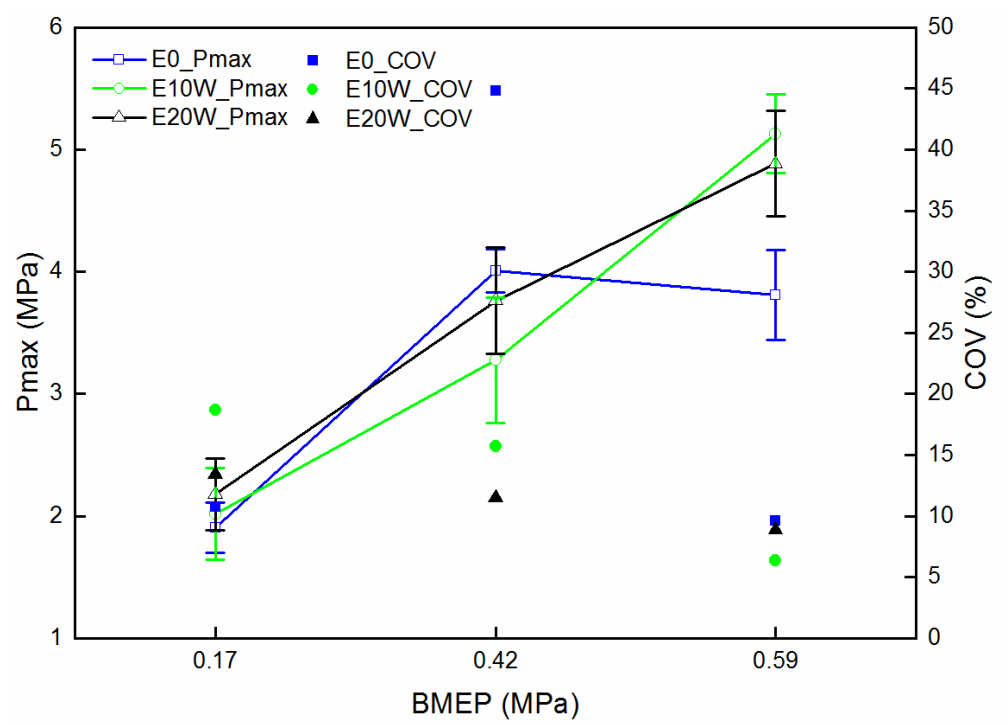

Figure 8. The cycle-by-cycle variations in Pmax for E0, E10W and E20W under three various loads.

\subsection{The Relationship between Noise Emission Level and Combustion Parameters}

According to Zhuang et al. [55], the higher cyclic variation in an engine increases the tendency to knock, thus increasing noise emission. Meanwhile, the noise emission by an SI engine leads to the cyclic variations as well as knock tendency. Therefore, the relation between exhaust noise emission and combustion parameters, including $(d p / d \varphi)_{\max }$ and cyclic variations, is explored here. The $C O V_{\text {imep }}, C O V_{P \max }$ and $C O V_{(d p / d \varphi) m a x}$ data are used because the $C O V_{\text {imep }}$ and $C O V_{\text {Pmax }}$ are the general representative parameters of cyclic variation and the $(d p / d \varphi)_{\max }$ is an important parameter in noise emission. Figure 9 illustrates the relationship between these two parameters for three fuels. It can be found that a higher sound pressure level is accompanied by higher $(d p / d \varphi)_{\max }$ for hydrous ethanol-gasoline blends at the tested conditions. This is attributed to the higher octane number of hydrous ethanol, which indicates longer ignition delay. More air-fuel mixtures are accumulated in the cylinder; thus, the instantaneous ignition leads to a higher pressure rise. As the $(d p / d \varphi)_{\max }$ increases, the strike between piston and linear becomes stronger, leading to higher noise emission levels. This observation is consistent with that of Giakoumis [56], who reported that the sound pressure level with the addition of ethanol is lower due to higher $(d p / d \varphi)_{\max }$.

As shown in Figure 9, the lower values of $C O V_{\text {imep }}$ and $C O V_{P \max }$ with a higher sound pressure level are observed for the blended fuels. Therefore, these two combustion parameters do not affect the exhaust noise emission, as expected. Notably, $C O V_{P \max }$ is almost below $20 \%$ for the three fuels, and the change in $C O V_{P \max }$ is not obvious with the increase in noise; that is, a slight decrease in $C O V_{P \max }$ will have a great impact on noise. $C O V_{P \max }$ is also a characterization of the $(d p / d \varphi)_{\max }$, which further confirms that the $(d p / d \varphi)_{\text {max }}$ is a crucial factor in the generation of an engine's noise. In addition, as Nikhil Sharma [27] suggested, the noise emission is not only affected by the fluctuation but also by the knocking of SIEs. They also pointed out that the combustion parameters, such as pressure rise rate and HRR, have a certain effect on combustion noise emission. Chetankumar et al. [57] carried out further research on the relation between HRR and noise emission, finding that the higher $H R R_{\max }$ is accomplished by a higher combustion noise level. Based on our current research, the cyclic variation may not dominate the exhaust noise emission of an engine, so further research is still necessary to figure out the relation between other combustion parameters and noise emission. 


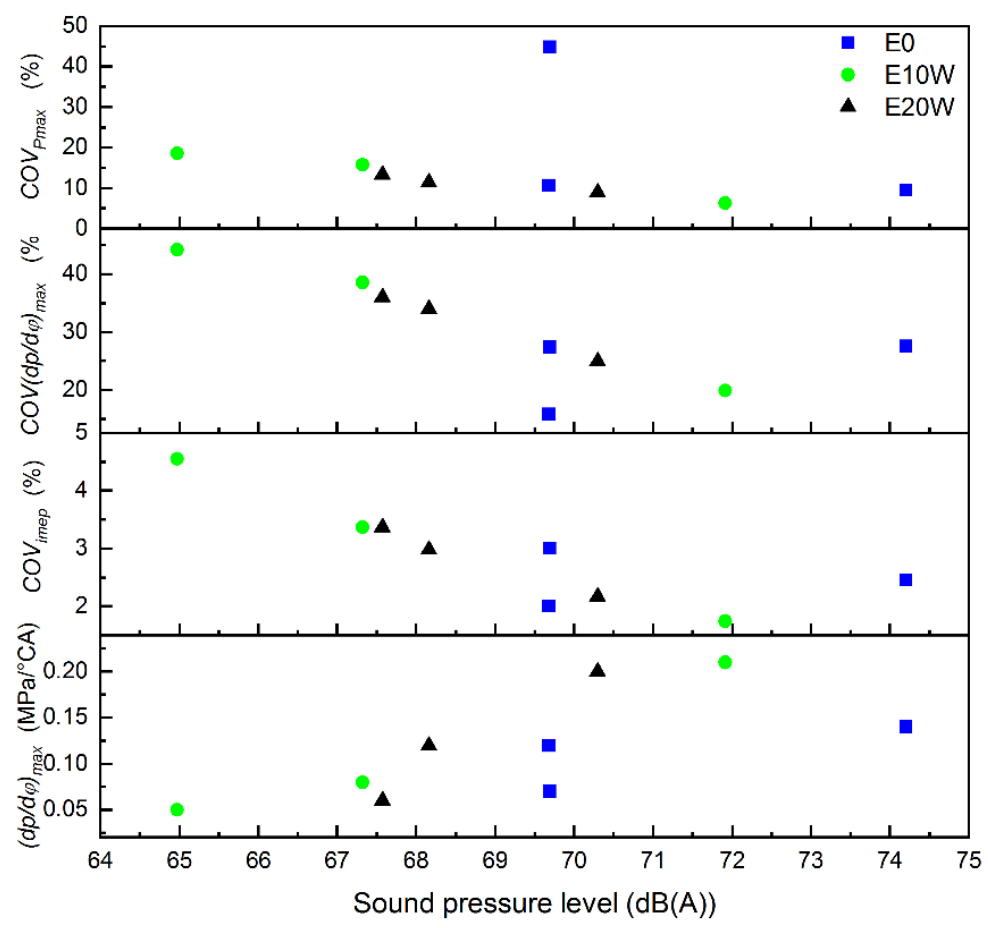

Figure 9. The relationship between noise emission level and combustion parameters.

In summary, combustion noise is closely related to $(d p / d \varphi)_{\max }$ and HRR. Under high load conditions, a large amount of premixed combustion will lead to an increase in HRR, $(d p / d \varphi)_{\max }$ and combustion noise. However, when the $(d p / d \varphi)_{\max }$ exceeds a certain value, it may produce more intense noise, which is known as running harshly of ICEs. The research shows that the combustion noise of a gasoline engine is mainly reflected in the middle frequency band (1000-10,000 Hz); the combustion noise dominates [58]. Therefore, in future work, the author will focus on the internal relationship between the $(d p / d \varphi)_{\max }$ and HRR and the engine's noise, using the vibration acoustics knowledge to achieve deeper research, providing some interesting information for further analysis.

\section{Conclusions}

Combustion noise is influenced by the combustion processes, especially the cyclic variation in the engine combustion. However, the inter-relationship of combustion characteristics and engine noise remains poorly understood. Furthermore, in terms of research content, since the load has a great influence on the combustion noise, the load becomes the core parameter to study the influencing factors of combustion noise. Therefore, in this work, exhaust noise emission, combustion characteristics and cycle-by-cycle variations in hydrous ethanol-gasoline blends have been investigated on a port fuel injection engine at a stable speed of $2000 \mathrm{r} / \mathrm{min}$ under different load conditions of $0.17,0.42$ and $0.59 \mathrm{MPa}$ BMEP. The authors seek to explore this significant gap through the study presented in this paper, and the vibration study of the noise output by the engine needs to be further studied. The results show that the combustion cycle variation can be reduced by mixing hydrous ethanol. According to the detailed experimental data, the following conclusions are drawn.

(1) Under the tested conditions, the noise emission level of the blends is lower than that of gasoline due to the oxygen content and vaporization heat of hydrous ethanol. The results of exhaust back pressure are in agreement with the trend of noise emission at medium and high loads.

(2) In comparison with pure gasoline, the Pmax with the addition of hydrous ethanol is lower than pure gasoline at a low load and becomes high at medium and high loads. Meanwhile, the $(d p / d \varphi)_{\max }$ of E0 is higher than hydrous ethanol-gasoline blends at 
most tested loads. E10W shows slightly higher Pmax and $(d p / d \varphi)_{\max }$ than E20W at low and medium loads.

(3) In terms of cyclic variations, E10W has the highest $C O V_{\text {imep }}$ and $C O V_{(d p / d \varphi) \text { max }}$, followed by E20W and E0 under low and medium loads. However, both blends exhibit lower $C O V_{\text {imep }}$ and $C O V_{(d p / d \varphi) m a x}$ than E0 under a high load.

(4) Combustion noise is closely related to $(d p / d \varphi)_{\text {max }}$, and the exhaust noise emission level of hydrous ethanol-gasoline blends exhibits a positive connection with $(d p / d \varphi)_{\text {max }}$. However, the cyclic variation does not dominate the noise emission. Further research is still needed to fill this gap.

Author Contributions: The contributions of the authors are summarized as follows: Conceptualization, Z.C.; methodology, J.D. and L.W.; software, C.W. and H.Z.; investigation, J.D. and C.W.; data curation, Z.C.; writing-original draft preparation, J.D.; formal analysis, J.D. and H.Z.; writingreview and editing, Z.C., H.Z. and J.D.; visualization, J.D.; supervision, Z.C. and H.Z.; project administration, Z.C. All authors have read and agreed to the published version of the manuscript.

Funding: This research was funded by the National Natural Science Foundation of China, grant number 51866002.

Institutional Review Board Statement: Not applicable.

Informed Consent Statement: Not applicable.

Data Availability Statement: Not applicable.

Acknowledgments: The authors kindly recognize the technical support provided by Jimin $\mathrm{Ni}$, Department of Automotive Engineering, Tongji University.

Conflicts of Interest: The authors declare no conflict of interest.

\section{Abbreviations}

$\begin{array}{ll}\text { BMEP } & \text { brake means effective pressure } \\ C O V & \text { coefficient of variation } \\ C O V_{\text {imep }} & \text { coefficients of variation in indicated mean effective pressure } \\ C O V_{\text {Pmax }} & \text { coefficients of variation in maximum pressure } \\ C O V_{(d p / d \varphi) \max } & \text { coefficients of variation in maximum pressure rise rate } \\ \text { CI } & \text { compression ignition } \\ (d p / d \varphi)_{\max } & \text { maximum pressure rise rate } \\ \text { E0 } & \text { pure gasoline } \\ \text { E10W } & 10 \% \text { hydrous ethanol plus } 90 \% \text { gasoline, by volume } \\ \text { E20W } & \text { 20\% hydrous ethanol plus } 80 \% \text { gasoline, by volume } \\ \text { FFT } & \text { fast Fourier transform } \\ \text { HRR } & \text { heat release rate } \\ \text { ICEs } & \text { internal combustion engines } \\ \text { IMEP } & \text { indicated mean effective pressure } \\ \text { Pmax } & \text { peak in-cylinder pressure } \\ \text { SI } & \text { spark-ignition } \\ \text { SIEs } & \text { spark-ignition engines }\end{array}$

\section{References}

1. Liu, J.; Dumitrescu, C.E. Analysis of Two-Stage Natural-Gas Lean Combustion inside a Diesel Geometry. Appl. Therm. Eng. 2019, 160, 114116. [CrossRef]

2. Liu, J.; Dumitrescu, C.E. Methodology to Separate the Two Burn Stages of Natural-Gas Lean Premixed-Combustion inside a Diesel Geometry. Energy Convers. Manag. 2019, 195, 21-31. [CrossRef]

3. Zaharin, M.; Abdullah, N.R.; Masjuki, H.H.; Ali, O.M.; Yusaf, T. Evaluation on physicochemical properties of iso-butanol additives in ethanol-gasoline blend on performance and emission characteristics of a spark-ignition engine. Appl. Therm. Eng. 2018, 144, 960-971. [CrossRef]

4. Wang, C.; Zeraati-Rezaei, S.; Xiang, L.; Xu, H. Ethanol blends in spark ignition engines: RON, octane-added value, cooling effect, compression ratio, and potential engine efficiency gain. Appl. Energy 2017, 191, 603-619. [CrossRef] 
5. Pan, S.; Li, X.; Han, W.; Huang, Y. An experimental investigation on multi-cylinder RCCI engine fueled with 2-butanol/diesel. Energy Convers. Manag. 2017, 154, 92-101. [CrossRef]

6. Martínez-Boggio, S.D.; Curto-Risso, P.L.; Medina, A.; Hernández, A.C. Simulation of cycle-to-cycle variations on spark ignition engines fueled with gasoline-hydrogen blends. Int. J. Hydrog. Energy 2016, 41, 9087-9099. [CrossRef]

7. Wei, H.; Feng, D.; Pan, M.; Pan, J.; Rao, X.; Gao, D. Experimental investigation on the knocking combustion characteristics of n-butanol gasoline blends in a DISI engine. Appl. Energy 2016, 175, 346-355. [CrossRef]

8. He, B.Q.; Liu, M.B.; Zhao, H. Comparison of combustion characteristics of n-butanol/ethanol-gasoline blends in a HCCI engine Energy Convers. Manag. 2015, 95, 101-109. [CrossRef]

9. Wang, X.; Chen, Z.; Ni, J.; Liu, S.; Zhou, H. The effects of hydrous ethanol gasoline on combustion and emission characteristics of a port injection gasoline engine. Case Stud. Therm. Eng. 2015, 6, 147-154. [CrossRef]

10. Li, T.; Zhang, X.Q.; Wang, B.; Guo, T.; Shi, Q.; Zheng, M. Characteristics of non-evaporating, evaporating and burningsprays of hydrous ethanol diesel emulsified fuels. Fuel 2017, 191, 251-265. [CrossRef]

11. Roso, V.R.; Santos, N.D.S.A.; Alvarez, C.E.C.; Rodrigues Filho, F.A.; Pujatti, F.J.P.; Valle, R.M. Effects of mixture enleanment in combustion and emission parameters using a flex-fuel engine with ethanol and gasoline. Appl. Therm. Eng. 2019, 153, 463-472. [CrossRef]

12. Schifter, I.; Diaz, L.; Gómez, J.P.; Gonzalez, U. Combustion characterization in a single cylinder engine with mid-level hydrated ethanol-gasoline blended fuels. Fuel 2013, 103, 292-298. [CrossRef]

13. Luo, M.; O. El-Faroug, M.; Yan, F.; Wang, Y. Particulate matter and gaseous emission of hydrous ethanol gasoline blends fuel in a port injection gasoline engine. Energies 2017, 10, 1263. [CrossRef]

14. Seifi, M.R.; Hassan-Beygi, S.R.; Ghobadian, B.; Desideri, U.; Antonelli, M. Experimental investigation of a diesel engine power, torque and noise emission using water-diesel emulsions. Fuel 2016, 166, 392-399. [CrossRef]

15. Deng, X.; Chen, Z.; Wang, X.; Zhen, H.; Xie, R. Exhaust noise, performance and emission characteristics of spark ignition engine fuelled with pure gasoline and hydrous ethanol gasoline blends. Case Stud. Therm. Eng. 2018, 12, 55-63. [CrossRef]

16. Liang, J.; Xiao, D.; Zhang, Q.; Chen, Z.; Zheng, Z. Combined impact of alcohol-fuel properties on performance and emissions characteristics with low-temperature combustion in a diesel engine. J. Energy Eng. 2021, 147, 04021018. [CrossRef]

17. da Costa, R.B.R.; Rodrigues Filho, F.A.; Coronado, C.J.; Teixeira, A.F.; Netto, N.A.D. Research on hydrous ethanol stratified lean burn combustion in a DI spark-ignition engine. Appl. Therm. Eng. 2018, 139, 317-324. [CrossRef]

18. Venugopal, T.; Sharma, A.; Satapathy, S.; Ramesh, A.; Gajendra Babu, M.K. Experimental study of hydrous ethanol gasoline blend (E10) in a four stroke port fuel-injected spark ignition engine. Int. J. Energy Res. 2013, 37, 638-644. [CrossRef]

19. Wang, Y.; Luo, M.; El-Faroug, M.O. The influence of hydrous ethanol gasoline on cycle-to-cycle variation of a spark ignition engine. Therm. Sci. 2018, 22, 1373-1384. [CrossRef]

20. Niculescu, R.; Clenci, A.; Iorga-Siman, V. Review on the use of diesel-biodiesel-alcohol blends in compression ignition engines Energies 2019, 12, 1194. [CrossRef]

21. Shukla, P.C.; Belgiorno, G.; Di Blasio, G.; Agarwal, A.K. Alcohol as an Alternative Fuel for Internal Combustion Engines; Springer: Singapore, 2021.

22. Nilaphai, O.; Komanee, K.; Chuepeng, S. Expansion heat release and thermal efficiency of acetone-butanol-ethanol-diesel blended fuel (ABE20) combustion in piston engine. Fuel 2022, 309, 122214. [CrossRef]

23. Tongroon, M.; Chuepeng, S. Adjacent combustion heat release and emissions over various load ranges in a premixed direct injection diesel engine: A comparison between gasoline and ethanol port injection. Energy 2022, 243, 122719. [CrossRef]

24. Asad, U.; Kumar, R.; Zheng, M.; Tjong, J. Ethanol-fueled low temperature combustion: A pathway to clean and efficient diesel engine cycles. Appl. Energy 2015, 157, 838-850. [CrossRef]

25. Patel, C.; Tiwari, N.; Agarwal, A.K. Experimental investigations of Soyabean and Rapeseed SVO and biodiesels on engine noise, vibrations, and engine characteristics. Fuel 2019, 238, 86-97. [CrossRef]

26. Giakoumis, E.G.; Rakopoulos, C.D.; Dimaratos, A.M.; Rakopoulos, D.C. Combustion noise radiation during the acceleration of a turbocharged diesel engine operating with biodiesel or n-butanol diesel fuel blends. Proc. Inst. Mech. Eng. Part D J. Automob. Eng. 2012, 226, 971-986. [CrossRef]

27. Sharma, N.; Patel, C.; Tiwari, N.; Agarwal, A.K. Experimental investigations of noise and vibration characteristics of gasolinemethanol blend fuelled gasoline direct injection engine and their relationship with combustion characteristics. Appl. Therm. Eng. 2019, 158, 113754. [CrossRef]

28. Li, F.; Chen, Z.; Deng, X.; Xie, R. Exhaust noise and emission characteristics of engine fueled with hydrous ethanol gasoline. Veh. Engine 2018, 237, 41-44.

29. Hoseinpour, M.; Sadrnia, H.; Tabasizadeh, M.; Ghobadian, B. Evaluation of the effect of gasoline fumigation on performance and emission characteristics of a diesel engine fueled with B20 using an experimental investigation and TOPSIS method. Fuel 2018, 223, 277-285. [CrossRef]

30. López, A.F.; Cadrazco, M.; Agudelo, A.F.; Corredor, L.A.; Vélez, J.A.; Agudelo, J.R. Impact of n-butanol and hydrous ethanol fumigation on the performance and pollutant emissions of an automotive diesel engine. Fuel 2015, 153, 483-491. [CrossRef]

31. Nour, M.; Attia, A.M.; Nada, S.A. Improvement of CI engine combustion and performance running on ternary blends of higher alcohol (Pentanol and Octanol)/hydrous ethanol/diesel. Fuel 2019, 251, 10-22. [CrossRef] 
32. Yusoff, M.N.A.M.; Zulkifli, N.W.M.; Masjuki, H.H.; Harith, M.H.; Syahir, A.Z.; Khuong, L.S.; Alabdulkarem, A. Comparative assessment of ethanol and isobutanol addition in gasoline on engine performance and exhaust emissions. J. Clean. Prod. 2018, 190, 483-495. [CrossRef]

33. Higashiyama, J.; Iwamoto, J. Experimental study of exhaust noise generated by pulsating flow downstream of pipe end. JSAE Rev. 1999, 20, 73-79. [CrossRef]

34. Pinzi, S.; Redel-Macías, M.D.; Leiva-Candia, D.E.; Soriano, J.A.; Dorado, M.P. Influence of ethanol/diesel fuel and propanol/diesel fuel blends over exhaust and noise emissions. Energy Procedia 2017, 142, 849-854. [CrossRef]

35. Bai, B.; Ni, B.; Chen, Z.; Su, J. Research on the effects of moisture ethanol-gasoline blended fuel on the engine exhaust noise. Small Intern. Combust. Engine Veh. Tech. 2017, 46, 61-65. (In Chinese)

36. Yu, X.; Wu, H.; Du, Y.; Tang, Y.; Liu, L.; Niu, R. Research on cycle-by-cycle variations of an SI engine with hydrogen direct injection under lean burn conditions. Appl. Therm. Eng. 2016, 109, 569-581. [CrossRef]

37. Park, S.H.; Suh, H.K.; Lee, C.S. Effect of bioethanol-biodiesel blending ratio on fuel spray behavior and atomization characteristics Energy Fuels 2009, 23, 4092-4098. [CrossRef]

38. Varatharajan, K.; Cheralathan, M. Influence of fuel properties and composition on NOx emissions from biodiesel powered diesel engines: A review. Renew. Sustain. Energy Rev. 2012, 16, 3702-3710. [CrossRef]

39. Manente, V.; Johansson, B.; Tunestal, P. Partially Premixed Combustion at High Load Using Gasoline and Ethanol, a Comparison with Diesel; (No. 2009-01-0944) SAE Technical Paper 2009; SAE International: Warrendale, PA, USA, 2009.

40. Li, W.; Ren, Y.; Wang, X.B.; Miao, H.; Jiang, D.M.; Huang, Z.H. Combustion characteristics of a compression ignition engine fuelled with diesel-ethanol blends. Proc. Inst. Mech. Eng. Part D J. Automob. Eng. 2008, 222, 265-274. [CrossRef]

41. Elfasakhany, A. Experimental study on emissions and performance of an internal combustion engine fueled with gasoline and gasoline/n-butanol blends. Energy Convers. Manag. 2014, 88, 277-283. [CrossRef]

42. Qian, Y.; Liu, G.; Guo, J.; Zhang, Y.; Zhu, L.; Lu, X. Engine performance and octane on demand studies of a dual fuel spark ignition engine with ethanol/gasoline surrogates as fuel. Energy Convers. Manag. 2019, 183, 296-306. [CrossRef]

43. Sun, L.; Zhou, L.; Zeng, K. Experimental Investigation of Cycle-by-Cycle Variations in a Natural Gas/Diesel Dual Fuel Engine with EGR; (No. 2013-01-0853) SAE Technical Paper 2013; SAE International: Warrendale, PA, USA, 2013.

44. Duan, X.; Liu, J.; Yuan, Z.; Guo, G.; Liu, Q.; Tang, Q.; Guan, J. Experimental investigation of the effects of injection strategies on cycle-to-cycle variations of a DISI engine fueled with ethanol and gasoline blend. Energy 2018, 165, 455-470. [CrossRef]

45. Schifter, I.; Diaz, L.; Rodriguez, R.; Gómez, J.P.; Gonzalez, U. Combustion and emissions behavior for ethanol-gasoline blends in a single cylinder engine. Fuel 2011, 90, 3586-3592. [CrossRef]

46. Reyes, M.; Tinaut, F.V.; Giménez, B.; Pérez, A. Characterization of cycle-to-cycle variations in a natural gas spark ignition engine. Fuel 2015, 140, 752-761. [CrossRef]

47. Sen, A.K.; Zheng, J.; Huang, Z. Dynamics of cycle-to-cycle variations in a natural gas direct-injection spark-ignition engine. Appl. Energy 2011, 88, 2324-2334. [CrossRef]

48. Fujikawa, T.; Nomura, Y.; Hattori, Y.; Kobayashi, T.; Kanda, M. Analysis of cycle-by-cycle variation in a direct injection gasoline engine using a laser-induced fluorescence technique. Int. J. Engine Res. 2003, 4, 143-153. [CrossRef]

49. Wang, S.; Ji, C. Cyclic variation in a hydrogen-enriched spark-ignition gasoline engine under various operating conditions. Int. J. Hydrog. Energy 2012, 37, 1112-1119. [CrossRef]

50. Yasin, M.H.M.; Mamat, R.; Yusop, A.F.; Abdullah, A.A.; Othman, M.F.; Yusrizal, S.T.; Iqbal, S.T. Cylinder Pressure Cyclic Variations in a Diesel Engine operating with Biodiesel-Alcohol Blends. Energy Procedia 2017, 142, 303-308. [CrossRef]

51. Kumar, S.; Singh, N.; Prasad, R. Anhydrous ethanol: A renewable source of energy. Renew. Sustain. Energy Rev. 2010, 14, 1830-1844. [CrossRef]

52. Chen, Z.; Wang, L.; Zeng, K. Comparative study of combustion process and cycle-by-cycle variations of spark-ignition engine fueled with pure methanol, ethanol, and n-butanol at various air-fuel ratios. Fuel 2019, 254, 115683. [CrossRef]

53. Dowling, A.P.; Mahmoudi, Y. Combustion noise. Proc. Combust. Inst. 2015, 35, 65-100. [CrossRef]

54. Wei, M.; Nguyen, T.S.; Turkson, R.F.; Guo, G.; Liu, J. The effect of water injection on the control of in-cylinder pressure and enhanced power output in a four-stroke spark-ignition engine. Sustainability 2016, 8, 993. [CrossRef]

55. Zhuang, Y.; Qian, Y.; Hong, G. The effect of ethanol direct injection on knock mitigation in a gasoline port injection engine. Fuel 2017, 210, 187-197. [CrossRef]

56. Giakoumis, E.G.; Rakopoulos, C.D.; Dimaratos, A.M.; Rakopoulos, D.C. Exhaust emissions with ethanol or n-butanol diesel fuel blends during transient operation: A review. Renew. Sustain. Energy Rev. 2013, 17, 170-190. [CrossRef]

57. Patel, C.; Lee, S.; Tiwari, N.; Agarwal, A.K.; Lee, C.S.; Park, S. Spray characterization, combustion, noise and vibrations investigations of Jatropha biodiesel fuelled genset engine. Fuel 2016, 185, 410-420. [CrossRef]

58. Vasilyev, A.V. Automobile internal combustion engine pressure charging and gas-guide low frequency noise reduction using active sound sources. Akustika 2019, 34, 118-122. [CrossRef] 